\title{
Empathy in Frontline Employees: The Link between Unemployed and Manpower Employment Organization under Economic Recession
}

\author{
Anna Maria Mouza \\ International Hellenic University \\ Department of Business Administration \\ Terma Magnesias, 62124 Serres, Greece \\ Nektaria Tsigarida \\ International Hellenic University \\ Department of Business Administration \\ Terma Magnesias, 62124 Serres, Greece
}

\begin{abstract}
This research examines whether empathy constitutes a vital key between the manpower employment organization and unemployed, taking into account Greece's high unemployment rate. Due to the agency's front and backline employees' role to serve the public, they are recipients of the difficult unemployed situation. For this reason, the relevant literature and the employees' working context are presented. Given that empathy has become one of the significant issues of the organizational studies, this article provides useful implications for managerial practice and future researches. In particular, it can be valuable to policymakers regarding decision making in public organizations who serve vulnerable groups due to the financial recession to improve the provided services for increasing performance, public satisfaction, and reduced costs.
\end{abstract}

Keywords: Empathy, frontline employees, unemployed, manpower employment organization, public organizations, economic recession

\section{Introduction}

Due to the economic crisis in Greece, which has led to a significant rise in unemployment, the Greek manpower agency strives to successfully serve the increasing number of unemployed citizens. In this sense, high quality services are of crucial importance for the achievement of the organization's goals and are an essential factor for increasing citizens' satisfaction. Undoubtedly, under these circumstances, the manpower of the organization can reinforce its role and enhance its value to the public. Thus, front and backline employees must be also fully committed to their organization and highly involved in their job.

Particularly the frontline employees can be considered the organization's representatives, as they are the connecting link between the unemployed and the agency both interacting with each other. Thus, they play a vital role regarding the organization's image and the quality of the provided services given the everyday numerous requests of various kind. Hence, in order to better respond to the citizens' needs and demands it is necessary to develop a culture of feeling and emotions taking into account the existing bureaucracy (Vigoda- Gadot and Meisler 2010) and the limited number of the provided benefits and jobs.

This kind of innovative and creative service, based on feelings and emotions, will allow them to advance the mutual understanding and trust (Aggarwal et al. 2005). Additionally, will provide to the frontline employees the chance to thoroughly investigate and understand the problems of the unemployed people, becoming thus better prepared to face the task of finding the best solutions by providing support and cooperation. Therefore, empathy can comprise a strategic point (Burke 1999) advancing differentiation and enabling to successfully face the tremendous challenges revealed by the negative impact of the financial crisis. Focusing on such practices of emotional kind will improve the employees' and organization's performance, increase the clients' satisfaction and reduce the organization's economic costs (Kim et al. 2004). In respect to these, the scope of this research is to present the existing literature and the employees' working context, to examine whether empathy constitutes a vital key between the manpower employment organization and the unemployed. 


\section{Empathy in frontline services}

Theodor Lipps (1903) used the world "einhühlen", translated into "empathy" by Titchener (1909), to explain the persons' ability to perceive, understand and share others' emotions, a vital factor for interpersonal interaction (Leiberg and Anders 2006). The latter pointed out the result of empathy to react appropriately and presented two main approaches, the contagion-like manner, an imitative process, and the perspective-taking, focusing on one person's ability to understand another person's emotions throughout the cognitive process. Other researchers (De Vignemont and Singer 2006) indicated two essential roles of empathy, the epistemological, reporting the others' oncoming behavior, and the social, providing synergetic, positive and helpful behavior, all beneficial for an effective social communication. The lasts decades, empathy was explored and various measures were developed, others related to cognitive perception and others to emotional responsiveness (Caruso and Mayer 1998; Spreng et al. 2009).

In 1998, Goleman presented empathy, as one of the main five competencies to evaluate Emotional Intelligence, referred as the persons' ability not only to recognize its own feelings and well manage its emotions, but also those of others, for personal motivation. In 2001, Goleman et al. included empathy in "social awareness", one of the four proposed components of the Emotional Intelligent, presenting the capabilities which determine how to manage relationships through social competence. Further, in 2002 (Goleman et al.) empathy was recognized as the leaders' ability to sense and feel the others' emotions, to understanding their point of view, in order to obtain the best communication with people of different cultures and backgrounds. Also, Goleman (2013) distinguished three kinds of empathy; the cognitive empathy (taking the others' perspective), the emotional empathy (feeling the others' distress) and empathetic concern (feeling the others pain and instinctively want to help them).

Regarding health care professional, empathy was highlighted (Mercer and Reynolds 2002) as a multi-dimensional attribute regarding the professionals' capability to communicate, understand the clients' needs, and to act in a helpful way. Significantly, many researches were undertaken to examine the components of empathy, as well as gender and specialty differences, among physicians (Hojat et al. 2002b) and medical students (Newton et al. 2000). Also, empathy was associated with the medical students' clinical competence and gender, where women presented higher levels (Hojat et al. 2002a; Kataoka et al. 2009). Faye et al. (2011) found that male medical postgraduate students, the married, and those who experienced serious problems in their life, presented higher levels of empathy. From the patients' point of view, physicians' empathy was proven to increase their satisfaction and compliance, where information exchange, interpersonal trust and partnership were the mediating factors (Kim et al. 2004).

Empathy was recognized as an important component for building relations between salespersons and clients (Varca 2004), increasing customer satisfaction (Wieseke et al. 2012), trust (Aggarwal et al. 2005), and rapport, thus, advancing the possibilities in sales (Spiro et al 1976). Besides, sellers with empathetic concern were prone to adaptive selling intention and therefore can adjust their behavior according to customers' characteristics (Giacobbe et al. 2006), when a positive relation was found between employees' empathetic abilities and customers' need perception (Homburg et al. 2009). Also, Ramachandran et al. (2011) suggested that the employees' ability to appraise the customers' feelings and hence showing empathy, was positively related to experiencing the required emotions. Additionally, a positive effect was found between emotional labor (Pugliesi 1999) and empathy (Varca 2009) on stress, when in another research, empathetic employees, presented also high emotional intelligence, regulating their emotions, thus minimizing their stress levels (Itani and Inyang 2015).

In the last decades the public employment agencies reorganized their structure (Glinsner et al. 2018), as it was recognized that the most essential challenge was to be more humane and care, rather than efficient (Newman et al. 2009). In this case, they mainly were engaged to the unemployed service orientation rather than bureaucracy. This changed the way of frontline employees' work adapting more affective practices, where empathy is considered an essential element, leading to agents' work effectiveness (Glinsner et al. 2018). Also, emotional labor presents numerous dimensions, where rapport and emotional engagement are vital to increase the employees' abilities to understand, communicate and empathize with others (Newman et al. 2009). Thus, in order to approach them and to establish friendly and trustworthy relations, public frontline employment agents show empathy and understanding for the situation of the unemployed (Penz et al. 2017). Additionally, through the use of the counselling process called empathetic authority, they activate and motivate jobseekers to find job (McDonald and Marston 2005).

\section{Economic crisis and unemployment}

The radical reforms in Greece together with the restrictive fiscal policy imposed due to the economic crisis, had a direct negative impact on the labor market too. The economic recession led to increased rates of poverty and a decrease of the economic growth (Michálek and Výboštok 2018), to the loss of a large number of jobs and a rising at the unemployment rate (Ervasti et al. 2018) 
Thus, adversely affecting the citizens' mental health and wellbeing (Lahad et al. 2018). Also it is noted that in Greece the $17 \%$ of the active population was recorded as long-term unemployed, having the lowest employment rate for 2016 (56.2\%), compared to the other European Union countries (Kraatz and Dessimirova 2016). Under these circumstances, the responsible organization for employment of the available workforce in Greece, in cooperation with relevant European bodies, redefined its business model. The main point was to tackle unemployment more effectively with the right planning. This was implemented by expanding and improving the services provided to the workforce so as to strengthen its role in the labor market, aiming to the successful realization of the redefined labor policies in the agency's business model (Kraatz 2015).

Employees, because of their positions in the organization, became the recipients of the unemployed difficult situation due to the consequences on their lives, as a result of the severe economic reforms. Thus, considering their everyday contact with the unemployed people, they are continuously experiencing the unfavorable impact of unemployment on citizens, which not only refers to the loss of income but also to the difficulty of finding new job, a prerequisite for their survival. Hence, in the daily process of serving unemployed people, serious problems are realized mainly referring to the latter's inability to have access to the electronic services of the organization, due to the lack of proper skills and the strong difficulty to travel for visiting the various agency's services, due to financial constraints. In this context, the employees, particularly the frontline ones, are the live testifiers of unfavorable feelings regarding future such as frustration, insecurity, anger, shame and anxiety.

Under these conditions, the employees make any effort to serve the unemployed people in the better and faster way, helping them to overcome bureaucratic problems, so that to face their needs with care and patience. Thus, especially for frontline people who have direct, daily and continuous contact and interaction with the unemployed, it is important, to develop a culture of empathy that will enable them to recognize and understand the needs of people, hence enhancing their daily service offering with respect and cooperation. In this sense, empathy is an indispensable component that is vital for shaping their work behavior for providing high-quality services.

Specifically, the frontline employees register applications for the provided allowances and benefits, they collect the necessary supporting documents for the filing of the applications and prepare the unemployed person's file. They record the regular presence of the unemployed in the organization in order to continue to receive the unemployment benefits, they release the certificates and provide the necessary clarifications to the citizens when needed. The backline staff work in departments related to benefits, finding jobs for the unemployed and the employment programs. They process the frontlines' submitted applications to complete the procedure, check the completeness of the files and issue decisions. Only in the absence of any supporting documents or in the need for additional clarification, they have to communicate with the unemployed. Regarding the organization's employment programs they mainly deal with the accountants and employers. Thus, they mainly carry out bureaucratic work without dealing with the public, except in very few cases. Thereby, frontline employees establish a guiding role regarding their duties, when the backline have mainly a processing role.

\section{Discussion}

In the manpower agency frontline employees are directly serving the unemployed when on the other hand, backline handle the administrative bureaucratic paperwork as well as legal issues. These are associated with the process of the submitted applications as to issue decisions and to forward various processes, without dealing with the ongoing public transaction.

Through the daily interaction with the unemployed, frontline employees share the unemployed problems, listen to their anxieties, and make the effort to help them in a quick and proper manner. Knowing that in many cases they don't have the needed technology and knowledge or the financial capacity to respond to the modern requirements, frontline employees seek to coordinate and facilitate the unemployed actions for gathering the necessary supporting documents, in order to efficiently handle their case without the need of unnecessary repeated visits to the organization. Thus, the frontline staff who is associated with the direct and primary provided services, is expected to present empathy (Goleman 2013) to serve the unemployed.

Backline employees also expected to be distinguished for their empathy feelings when they cannot cover the unemployed needs. This is mostly associated with the nature and the backline employees' duties, as they are more related with the final decisions regarding the unemployed applications, therefore it is expected to have an emotional involvement regarding their issues, as they can understand their difficult position, and they are aware what they face (Goleman 2013), when the outcomes are not positive for them. 
Additionally, intrinsic motivation in work must be investigated both for back and frontline employees, as many researchers have found that public-service motivation is based more on intrinsic than extrinsic rewards (Houston 2000; Georgellis et al. 2010). Additionally, Gwinner et al. (2005) indicated that intrinsic motivation influences the employees' interpersonal adaptive and service-offering behavior. In this case is expected that the employees must adapt their attitude based on the unemployed needs to serve them for having the best results, where intrinsic motivation can be considered as an important factor to achieve their goals. It is recalled that the frontline staff is becoming a daily recipient of the difficult situations faced by the unemployed and their feelings. They recognize that loss of work results in cuts in various sectors of their lives and they share their anxiety. Thus, it is expected to present empathy to understand their needs as to serve them in the best way, by adapting their behavior on behalf of them through intrinsic motivation.

Goleman also (2004) revealed the crucial importance of the employees' commitment to the organization, deriving from their love for their job, components strongly associated with intrinsic motivation. In this case there must be also explored the employees' willing to achieve the organizations' goals through their organizational commitment, which has been already found to be related to intrinsic motivation (Crewson 1997), regarding the required processes to serve the unemployed.

Also, many studies have already reported a positive relation between job satisfaction and organizational commitment (Mahmoud 2008; Back et al. 2011), indicating that high levels of satisfaction lead also to the employees' greater commitment to organizations' goals (Kim et al. 2005), issues that is proposed to be investigated as frontline employees is expected to better understand the consequences of the unemployment and appreciate more the value of working to the specific organization. Thus, satisfied employees are making the required work to fulfill the organizations' goals, as they feel that their main objective is to serve the unemployed.

Furthermore, (Borzaga and Tortia 2006) have also reported the significant influence between satisfaction and intrinsic motivation. In this case, the employees are driven by an inside desire to empathize and provide the best possible service to the unemployed (Taylor 2007), leading to work satisfaction, issue that is worthy to be explored for both front and backline employees.

\section{Future researches}

Future researchers must examine the employees' attitudes based on the public assessment and satisfaction regarding the provided services. Additionally, not only quantitative but also qualitative researches should be carried on to provide further information for tracing the gaps and develop the required training programs in order to enhance the employees' skills for active listening and empathetic responding. Furthermore, the essential role of the managers is to examine for supporting, motivating and encouraging the effectiveness of the frontline employees, as they have a leading role in the accomplishment of the organization's strategic goals.

\section{Conclusion}

In this study we presented the relative literature, the working context and the provided services of the front and backline employees, working in the Greek manpower agency, taking in to account the nature of their work, to serve the unemployed suffering from the negative consequences of the ongoing economic crisis.

Considering the above, and given the vital role of empathy, it is proposed that it is important to explore whether front and back line employees present high levels of empathy due to their specific duties when serving the unemployed. Additionally it is proposed that employees' intrinsic motivation, commitment to organizations' goals and job satisfaction and their associations must be examined.

Future researches can be valuable especially to policymakers for decision making concerning the importance of the required empathetic behaviors of the frontline employees in public manpower employment organizations, and others too, which serve vulnerable groups due to the economic crisis. Thereby they will be able to expand and improve their provided services for increased employees' and organizations' performance, public satisfaction and reduced costs.

\section{References}

Aggarwal, P., Castleberry, S. B., Ridnour, R., \& Shepherd, C. D. (2005). Salesperson empathy and listening: impact on relationship outcomes. Journal of Marketing Theory and Practice, 13(3), 16-31.

Back, K. J., Lee, C. K., \& Abbott, J. (2011). Internal relationship marketing: Korean casino employees' job satisfaction and organizational commitment. Cornell Hospitality Quarterly, 52(2), 111-124. 
Borzaga, C., \& Tortia, E. (2006). Worker motivations, job satisfaction, and loyalty in public and nonprofit social services. Nonprofit and voluntary sector quarterly, 35(2), 225-248.

Burke, F. (1999). Ethical decision-making: Global concerns, frameworks, and approaches. Public Personnel Management, 28(4), 529-540.

Ervasti, H., Kouvo, A. \& Venetoklis, T. (2019). Social and Institutional Trust in Times of Crisis: Greece, 2002-2011. Social Indicators Research, 141(3), 1207-1231.

Caruso, D. R., \& Mayer, J. D. (1998). A measure of emotional empathy for adolescents and adults. Unpublished manuscript, 713-726.

Crewson, P. E. (1997). Public-service motivation: Building empirical evidence of incidence and effect. Journal of public administration research and theory, 7(4), 499-518.

De Vignemont, F., \& Singer, T. (2006). The empathic brain: how, when and why? Trends in cognitive sciences, $10(10), 435-441$.

Faye, A., Kalra, G., Swamy, R., Shukla, A., Subramanyam, A., \& Kamath, R. (2011). Study of emotional intelligence and empathy in medical postgraduates. Indian Journal of Psychiatry, 53(2), 140-144.

Georgellis, Y., Iossa, E., \& Tabvuma, V. (2010). Crowding out intrinsic motivation in the public sector. Journal of Public Administration Research and Theory, 21(3), 473-493.

Giacobbe, R. W., Jackson Jr, D. W., Crosby, L. A., \& Bridges, C. M. (2006). A contingency approach to adaptive selling behavior and sales performance: Selling situations and salesperson characteristics. Journal of Personal Selling \& Sales Management, 26(2), 115-142.

Glinsner, B., Sauer, B., Gaitsch, M., Penz, O., \& Hofbauer, J. (2018). Doing gender in public services: Affective labour of employment agents. Gender, Work \& Organization, 1-17.

Goleman, D. (2013). The focused leader. Harvard Business Review, 91(12), 50-60.

Goleman, D. (2004). What makes a leader? (Best of HBR). Harvard Business Review, 82 (1), pp. 82-91.

Goleman, D. (1998). Working with Emotional Intelligence. Random House LLC.

Goleman, D., Boyatzis, R., \& McKee, A. (2001). Primal leadership: The hidden driver of great performance. Harvard business review, 79(11), 42-53.

Goleman, D., Boyatzis, R., \& McKee, A. (2002). Primal Leadership: Realizing the Power of Emotional Intelligence. Harvard Business Review Press; 1 edition (March 15, 2002), p.255.

Gwinner, K. P., Bitner, M. J., Brown, S. W., \& Kumar, A. (2005). Service customization through employee adaptiveness. Journal of Service Research, 8(2), 131-148.

Hojat, M., Gonnella, J. S., Mangione, S., Nasca, T. J., Veloski, J. J., Erdmann, J. B., Callahan, C.A., \& Magee, M. (2002a). Empathy in medical students as related to academic performance, clinical competence and gender. Medical education, 36(6), 522-527.

Hojat, M., Gonnella, J. S., Nasca, T. J., Mangione, S., Vergare, M., \& Magee, M. (2002b). Physician empathy: definition, components, measurement, and relationship to gender and specialty. American Journal of Psychiatry, 159(9), 1563-1569.

Homburg, C., Wieseke, J., \& Bornemann, T. (2009). Implementing the marketing concept at the employee-customer interface: the role of customer need knowledge. Journal of Marketing, 73(4), 64-81.

Houston, D. J. (2000). Public-service motivation: A multivariate test. Journal of public administration research and theory, 10(4), 713-728.

Itani, O. S., \& Inyang, A. E. (2015). The effects of empathy and listening of salespeople on relationship quality in the retail banking industry: The moderating role of felt stress. International Journal of Bank Marketing, 33(6), 692716.

Kataoka, H. U., Koide, N., Ochi, K., Hojat, M., \& Gonnella, J. S. (2009). Measurement of empathy among Japanese medical students: psychometrics and score differences by gender and level of medical education. Academic Medicine, 84(9), 1192-1197.

Kim, S. S., Kaplowitz, S., \& Johnston, M. V. (2004). The effects of physician empathy on patient satisfaction and compliance. Evaluation \& the health professions, 27(3), 237-251.

Kim, W. G., Leong, J. K., \& Lee, Y. K. (2005). Effect of service orientation on job satisfaction, organizational commitment, and intention of leaving in a casual dining chain restaurant. International Journal of Hospitality Management, 24(2), 171-193.

Kraatz, S. (2015). Youth unemployment in Greece: Situation before the government change. Policy Department A: Economy and Scientific Policy, European Parliament, available at: www. europarl. europa. eu/studies Doi, 10, 35149 . 
Kraatz, S. \& Dessimirova D. (2016). Unemployment and Poverty: Greece and Other (Post-) Programme Countries. Policy Department A: Economy and Scientific Policy, European Parliament, available at: www. europarl. europa. eu/studies Doi, 10, 18242.

Lahad, M., Cohen, R., Fanaras, S., Leykin, D., \& Apostolopoulou, P. (2018). Resiliency and Adjustment in Times of Crisis, the Case of the Greek Economic Crisis from a Psycho-social and Community Perspective. Social Indicators Research, 135(1), 333-356.

Leiberg, S., \& Anders, S. (2006). The multiple facets of empathy: a survey of theory and evidence. Progress in brain research, 156, 419-440.

Lipps, T. (1903). Einfühlung, innere Nachahmung und Organenempfindungen. Archiv für die gesamte Psychologie 1:465-519.

Mahmoud, A. H. (2008). A study of nurses' job satisfaction: the relationship to organizational commitment, perceived organizational support, transactional leadership, transformational leadership, and level of education. European journal of scientific research, 22(2), 286-295.

McDonald, C., \& Marston, G. (2005). Workfare as welfare: governing unemployment in the advanced liberal state. Critical social policy, 25(3), 374-401.

Mercer, S. W., \& Reynolds, W. J. (2002). Empathy and quality of care. British Journal of General Practice, 52(Suppl), S9-12.

Michálek, A., \& Výbošt’ok, J. (2018). Economic Growth, Inequality and Poverty in the EU. Social Indicators Research, $1-20$.

Newman, M. A., Guy, M. E., \& Mastracci, S. H. (2009). Beyond cognition: Affective leadership and emotional labor. Public Administration Review, 69(1), 6-20.

Newton, B. W., Savidge, M. A., Barber, L., Cleveland, E., Clardy, J., Beeman, G., \& Hart, T. (2000). Differences in medical students' empathy. Academic Medicine, 75(12), 1215.

Penz, O., Sauer, B., Gaitsch, M., Hofbauer, J., \& Glinsner, B. (2017). Post-bureaucratic encounters: Affective labour in public employment services. Critical Social Policy, 37(4), 540-561.

Pugliesi, K. (1999). The consequences of emotional labor: Effects on work stress, job satisfaction, and well-being. Motivation and emotion, 23(2), 125-154.

Ramachandran, Y., Jordan, P. J., Troth, A. C., \& Lawrence, S. A. (2011). Emotional intelligence, emotional labour and organisational citizenship behaviour in service environments. International Journal of Work Organisation and Emotion, 4(2), 136-157.

Spiro, R. L., Perreault Jr, W. D., \& Reynolds, F. D. (1976). The personal selling process: A critical review and model. Industrial Marketing Management, 5(6), 351-363.

Spreng, R. N., McKinnon, M. C., Mar, R. A., \& Levine, B. (2009). The Toronto Empathy Questionnaire: Scale development and initial validation of a factor-analytic solution to multiple empathy measures. Journal of personality assessment, 91(1), 62-71.

Taylor, J. (2007). The impact of public service motives on work outcomes in Australia: a comparative multi- dimensional analysis. Public administration, 85(4), 931-959.

Titchener, E. B. (1909). Lectures on the experimental psychology of the thought-processes. Macmillan. New York.

Varca, P. E. (2004). Service skills for service workers: emotional intelligence and beyond. Managing Service Quality: An International Journal, 14(6), 457-467.

Varca, P. E. (2009). Emotional empathy and front line employees: does it make sense to care about the customer?. Journal of Services Marketing, 23(1), 51-56.

Vigoda- Gadot, E., \& Meisler, G. (2010). Emotions in management and the management of emotions: The impact of emotional intelligence and organizational politics on public sector employees. Public Administration Review, 70(1), 72-86.

Wieseke, J., Geigenmüller, A., \& Kraus, F. (2012). On the role of empathy in customer-employee interactions. Journal of Service Research, 15(3), 316-331. 